\title{
O CORPO NA OBRA DE MICHEL FOUCAULT E SUA PRESENÇA NO CAMPO DA EDUCAÇÃO FÍSICA
}

\author{
Pietrine Paiva Barbosa \\ Universidade Federal de Minas Gerais, Belo Horizonte, Minas Gerais, Brasil \\ Nathália Rodrigues Oliveira \\ Centro Universitário UNA, Belo Horizonte, Minas Gerais, Brasil
}

\begin{abstract}
Resumo
Devido a crescente influência das Ciências Humanas na área da Educação Física que sempre se desenvolveu a partir dos ideais das Ciências Biológicas, passam a circular na área formas de se investigar o corpo que trazem em comum aspectos políticos, culturais e históricos. No bojo deste cenário encontra-se Michel Foucault. Este artigo investiga nas obras do filósofo e a partir de comentadores, como se dá a fundamentação do conceito de Corpo em seu pensamento. Entende-se a partir da análise, o Corpo como uma superfície material, concreta, na qual se instala diferentes formas de Sujeito fabricadas por tecnologias políticas específicas e históricas. Tal análise possui sua validade para uma melhor compreensão das problematizações realizadas no cenário contemporâneo da Educação Física.
\end{abstract}

Palavras-chave: Corpo. Sujeito. Michel Foucault. Educação Física.

\section{Breve histórico: a presença do corpo na educação física como disciplina escolar}

A história da Educação mostra que a preocupação com o corpo tem sido presente nas práticas pedagógicas. Conforme afirma Louro (2000), os processos de escolarização estiveram (e ainda estão) preocupados em vigiar, controlar, corrigir e construir os corpos dos alunos. Quando pensamos na história da Educação Física no Brasil, por sua vez, percebemos que tal perspectiva também ocorreu (e ocorre) em sua prática nas instituições escolares.

Ainda no nascimento ${ }^{1}$ da Educação Física enquanto disciplina da escola, podemos percebê-la, segundo Bracht (1999), constituída a partir de forte influência militar, cumprindo a função de colaborar na construção de corpos saudáveis e dóceis, tendo em vista o processo produtivo do país. Por outro lado, também é possível notar que a área se construía legitimada pelo conhecimento médico-científico do corpo, que referendava as possibilidades, a necessidade e as vantagens de tal intervenção sobre o corpo.

Especialmente, com a implantação do Estado Novo, a partir de 1930, a Educação Física passa a funcionar como auxílio na construção de um novo homem, almejado pelo discurso estadonovista. Os trabalhos de Danailof e Soares (2002), assim como o de Danailof (2005) explicitam a educação do corpo estabelecida na época, e definem o corpo como registro das marcas de um tempo que vislumbra um futuro próspero para a nação.

\footnotetext{
${ }^{1}$ Período também contemplado por Vago (1999), Sousa e Vago (2003), Teixeira (2008) e Herold e Leonel (2010). 
Com o final da ditadura do Estado Novo, afirmam Nunes e Rúbio (2008), novas configurações políticas e sociais ocorreram, fazendo com que a Educação fosse mediada pelo desenvolvimento tecnológico e industrial. Dessa maneira, a partir de um discurso desenvolvimentista, o ensino passa a valorizar o rendimento e os melhores resultados dos estudantes. A peculiaridade do Esporte quanto atividade física regrada por regulamentos, especialização de papéis, competição, meritocracia e por apresentar condições para medir, quantificar e comparar resultados, faz dele um bom meio de preparar o homem daqueles tempos.

Já no período de Ditadura Militar², além da modernização do país, as preocupações se voltam para o controle social. Logo, o esporte e as competições escolares são impulsionados, sendo que, segundo Oliveira (2003), neste momento acontece à valorização de um mundo centrado em competição, concorrência, vitória e consagração, instaurando-se assim, o movimento de esportivização $o^{3}$ das aulas de Educação Física nas escolas, o qual trazia consigo o ideal de lutadores e vencedores.

Durante todo esse período, como relata Mazoni (2003), a Educação Física buscou atuar sobre "corpos-objetos": endireitando posturas, adestrando gestos, ensinando técnicas padronizadas e tentando fomentar um melhor desempenho mecânico da "máquina humana". Mesmo considerando a escola como um espaço onde existem tensões e resistências, pode-se afirmar que a definição dos conteúdos e procedimentos didáticos dessa área durante grande parte do século XX, apresentaram marcantes interferências de estratégias relacionadas ao uso e ao controle dos corpos pelas estruturas de poder, com fins políticos de regulação e manutenção da ordem. Sendo assim, por mais de 50 anos, o esporte competitivo, a cientificidade biomédica e a disciplina militar predominaram durante a formação dos professores dessa área no país. Tal herança trouxe, por muito tempo, o entendimento do corpo sinônimo de "máquina", com o objetivo de garantir seu melhor funcionamento orgânico. Essa visão é apresentada, principalmente, pela Ciência Biomédica, a qual é tradicionalmente vista como a mais correta e explicativa, conforme assinala Santos (1999). Essa percepção de corpo é entendida, muitas vezes, como a "Ciência da Verdade", que desvenda o mundo por meio de suas pesquisas, instrumentos e metodologias. Por isso, essa deveria ser, segundo esse raciocínio, a perspectiva sobre a qual o corpo deveria ser ensinado: um corpo universal, igual para todos, fundamentado pela figuração anatômica.

A partir dos anos 80, com a abertura democrática vivenciada no país e o aumento dos cursos de pós-graduação, esse quadro começa a se transformar. Percebe-se, então, uma crescente influência ${ }^{4}$ das Ciências Humanas na área da Educação Física que, conforme abordado anteriormente, desenvolvia-se, prioritariamente, a partir dos ideais das Ciências Biológicas. Sendo assim, surgem novas formas de compreensão do corpo dentro da área. Conforme destacam Martineli e Mileski (2012), a partir dos anos 80, a Educação Física e seus conteúdos passam por um processo de reflexão e crítica. Em uma pesquisa visando compreender quais as concepções de corpo (oriundas das Ciências Humanas) estiveram presentes nas produções científicas da área entre os anos de 1980 e 1990, tais autores destacam três vertentes, abordadas nos parágrafos seguintes.

A primeira perspectiva, segundo os autores, teve inicio em 1983, com a publicação do livro A educação física cuida do corpo... e "mente", de João Paulo Medina. Naquele período, o autor propunha uma reflexão crítica sobre o papel desempenhado pela disciplina, afirmando

\footnotetext{
${ }^{2}$ Período também contemplado por Pinto (2003).

${ }^{3} \mathrm{O}$ termo "esportivização" é entendido aqui como a passagem do esporte, nas aulas de educação física, de conteúdo escolarizado a conteúdo exclusivo, sendo gerador de uma nova forma de organizar o conhecimento, os espaços, tempos e relações sociais dentro e fora da escola. (Dantas Junior, 2008).
}

${ }^{4}$ Ludorf (2002) 
que um período de crise dessa área seria necessário para que os profissionais repensassem o problema do corpo na sociedade brasileira, recuperando-se, assim, um sentido mais humano para o último. Alguns anos depois, em 1987, o mesmo autor publicou o livro O Brasileiro $e$ seu corpo: educação e política do corpo, em que fazia reflexões sobre o tema, ancorando-se, principalmente, na Filosofia Fenomenológica (de Merleau-Ponty), no pensamento marxista e também na pedagogia freireana.

Na década de 90, marcada pela readequação das bases sociais ditas democráticas, destacaram-se os trabalhos de Jocimar Daólio e Carmem Lúcia Soares. O primeiro estruturava-se em investigações sobre o homem em suas relações sociais, entendendo o último como um construtor de significados para as suas ações no mundo. Dessa maneira, o autor entende o "corpo" como uma construção cultural que pode se diferir dependendo do conjunto de significados que a sociedade escreve no corpo de seus membros. Cabe ressaltar a influência da Antropologia Social (de Laplantine e Geertz) e da Sociologia (de Durkheim) nas obras do autor, conforme apontam Martineli e Mileski (2012). Já nos estudos de Carmem Lúcia Soares, o "corpo" é representado como algo histórico e submetido ao controle social. Ao longo de suas obras, é possível perceber a Educação e a Educação Física sistematizadas como instrumentos capazes de promover o controle sobre os corpos. Martineli e Mileski (2012), ao discorrerem sobre o livro Educação Física: raízes europeias e Brasil, explanam sobre a constituição da Educação Física enquanto disciplina pedagógica, evidenciando a forma como a ciência positivista influenciou as justificativas fundamentais da área. Nessa obra, a abordagem positivista adotou um modelo de conhecimento alicerçado, sobretudo, na biologia e na história natural. $\mathrm{O}$ homem é, então, explicado por essas ciências, fazendo com que os profissionais formados sob esta lógica dominassem apenas o conhecimento sobre o corpo biológico. Aqui, cabe destacar a grande influência da filosofia de Michel Foucault nos trabalhos da autora.

Mais recentemente, no campo da Educação, alguns autores organizam uma série de artigos sobre o tema do Corpo, trazendo boas contribuições para o campo da Educação Física. Em 2006, Marcus Aurélio Taborda de Oliveira lança o livro Educação do corpo na escola brasileira. Em 2007, Carmen Lúcia Soares organiza o livro Pesquisas sobre o corpo: ciências humanas e educação. No mesmo ano, outra coletânea é organizada por Edvaldo Souza Couto e Silvana Vilodre Goellner intitulada: Corpos Mutantes: Ensaios Sobre Novas (D)Eficiências Corporais. Tais autores também organizam em 2012 o livro O Triunfo do Corpo: Polêmicas Contemporâneas. Estes são alguns exemplos de importantes referências que problematizam o tema do corpo, abordando também o tema na Educação Física brasileira.

Podemos dizer que essas perspectivas trazem em comum uma forma de se compreender o Corpo levando em consideração aspectos históricos, políticos e sociais. Neste cenário, percebemos a presença do pensamento de Michel Foucault em algumas destas perspectivas. No âmbito das discussões sobre o Corpo presença no campo da Educação Física se dá com maior notoriedade a partir dos estudos de Carmem Lúcia Soares. Na atualidade também é possível encontrar tal presença nos trabalhos de outros autores, como Alex Branco Fraga, do qual apresentaremos algumas obras mais adiante neste texto. Assim, pretende-se neste artigo, a retomada do conceito de corpo na obra de Michel Foucault. Para isso, buscamos a compreensão do conceito a partir de uma releitura de seus livros, mais especificamente, As palavras $e$ as coisas, Vigiar e punir, História da sexualidade: a vontade de saber, História da sexualidade: o uso dos prazeres, História da sexualidade: o cuidado de si; e também na leitura de comentadores especialistas na obra do mesmo, renomados no contexto brasileiro. Com isso, espera-se contribuir para as discussões no campo da Educação Física, no qual, o conceito de Corpo possui grande relevância.

\section{O corpo em Michel Foucault}


Eu gostaria de dizer, antes de mais nada, qual foi o objetivo do meu trabalho nos últimos vinte anos. Não foi analisar o fenômeno do poder nem elaborar os fundamentos de tal análise. Meu objetivo, ao contrário, foi criar uma história dos diferentes modos pelos quais, em nossa cultura, os seres humanos tornaram-se sujeitos. (FOUCAULT, apud: Dreyfus e Rabinow, 2010, p. 273).

O trecho anterior diz respeito a uma entrevista com Michel Foucault, realizada em 1982. Por meio dessa citação, percebe-se que o Sujeito é o tema central investigado pelo filósofo. Sabe-se que o entendimento de Foucault sobre o corpo não é facilmente sistematizável e, dessa forma, faz-se necessário discorrer, brevemente, sobre os caminhos empreendidos pelo autor em suas análises sobre o sujeito para, posteriormente, abordarmos o Corpo propriamente dito.

Ao longo de seus trabalhos, Foucault tratou de três modos de objetivação que transformaram seres humanos em sujeitos. Em As palavras e as coisas ele procura isolar e descrever os sistemas de saber à três grandes fases do pensamento ocidental que ele denominou de Renascimento, Época Clássica e Modernidade. Após discorrer sobre as características peculiares dos dois primeiros, Foucault nos mostra que, em meados do século XVIII, surgiu o homem objetivado para o saber. Além disso, ele afirma que o fim da era da Representação, período no qual o conhecimento se caracterizava por uma relação de ordenação entre as ideias, decorre de uma modificação operada nos saberes da vida, da linguagem e do trabalho. Como relata Araújo (2008), o homem para o saber aparece quando surge a Biologia, que o apresenta como organismo vivo e a vida tendo suas próprias condições de evolução. A economia, por sua vez, o mostra como produtor, cujo trabalho depende do seu modo de produção. Por fim, a filologia, que o mostra como falante, tendo a língua suas regras próprias.

Machado (2007), revela que ao ser tematizado pelas ciências empíricas, o homem torna-se objeto do saber. Juntamente, há o nascimento de um novo tipo de filosofia, que tem como marco inicial a "revolução copernicana" realizada por Kant, que interroga aquele que conhece. Dreyfus e Rabinow (2010) complementam dizendo que o homem torna-se agora um sujeito entre objetos. Mas não é só isso, ele também entende que aquilo que tenta compreender não são apenas os objetos do mundo, mas a ele próprio, inclusive. Por isso Foucault denomina a modernidade como a idade do homem, período que se dá o nascimento das Ciências Humanas.

O estudo realizado em As palavras e as coisas pertence ao início da produção de Foucault, no entanto, já é possível notar que o autor não dá à figura de conhecimento homem um entendimento transcendental, no qual, ao destituirmos toda a estrutura social, teríamos acesso ao que ele realmente é. Ao vislumbrarmos o quadro geral de sua obra, percebemos como, ao longo da história, foram se constituindo subjetividades diversas e que estas não conduzem ao encontro de um possível fundamento do homem.

Juntamente com Fonseca (2011), percebe-se que em História da sexualidade: $O$ uso dos prazeres, Foucault trata do estilo de vida grego em suas práticas relacionadas ao sexo, nos seguintes domínios: cuidados com o corpo, com a casa e com a busca da verdade. Neste período da história, a questão dos prazeres fundava-se em condutas temperantes, moderadas e bem conduzidas eticamente. Em História da sexualidade: o cuidado de si, aborda problemas já presentes na Grécia Clássica, mas que os latinos tratarão de modo diferente. Encontra-se aqui, uma ética mais austera em que se ressalta um voltar-se para si próprio, um ocupar-se consigo mesmo.

\footnotetext{
${ }^{5}$ A descoberta essencial é que a faculdade de conhecer é legisladora ou, mais precisamente, que há algo de legislador na faculdade de conhecer.
} 
A partir destas leituras, fica claro que Foucault rejeita a ideia de um sujeito que existe a priori do mundo social, pois mostra como ao longo da história foram se constituindo diferentes tipos de subjetividades. Ou seja, o que existe para o autor são diferentes constituições de um sujeito, que não é dado definitivamente, mas que a cada instante é fundado e refundado na história. A esse respeito, Veiga-Neto (2011) esclarece que Foucault "dá as costas" para o sujeito produzido pelas metanarrativas ${ }^{6}$ iluministas: $O$ sujeito desde sempre aí, ou seja, ele não aceita a afirmação de que o sujeito é algo dado, que preexiste ao mundo social. Para ele, o sujeito é constituído.

Mas, e o Corpo? Ao investigarmos o que Foucault diz a esse respeito, percebemos a proximidade que seu pensamento sobre o tema trás com sua noção de Sujeito. Porém, diferentemente desse último, o Corpo preexiste ao mundo social. Mendes (2006) afirma que o corpo para Foucault é composto por carne, ossos, órgãos e membros, é matéria, literalmente, algo físico e concreto. No entanto, essa matéria física não é inerte, sem vida, mas sim uma superfície moldável, transformável e remodelável. Assim, esse corpo físico, material, sofre a ação das relações de $\operatorname{poder}^{7}$ que compõem tecnologias políticas específicas e históricas.

A partir desse entendimento é que se relaciona sua ideia de sujeito com o corpo. Como nos diz Fernandes (2012), a relação entre estes é explicada no sentido de mostrar que o primeiro não se reduz a um indivíduo corpóreo, mas é necessário um corpo que funcione como seu suporte, para o exercício de sua função. Nesse sentido, o que está em questão para Foucault não é propriamente o corpo, mas o sujeito de ação, produzido por uma exterioridade social, cultural e política. Isso quer dizer que é exatamente esse sujeito de ação, produzido pelo discurso, que dá forma e concretude ao corpo. No campo da Educação e da Educação Física por exemplo, podemos ver várias formas de sujeito sendo constituídas historicamente para atender à urgências específicas de cada época. Os discursos que circulavam sobre ser professor no início do século atendiam a demandas diferentes do que os que circulam na atualidade. Assim, cada época trás em si relações de forças compostas pela exterioridade social que irá fabricar certos tipos de sujeito e dar forma a diferentes tipos de corpos.

Como observa Prado Filho e Trisotto (2008), não se trata aqui da naturalidade, mas da historicidade dos corpos, no plural, porque, percorrendo a história, nota-se a circulação de toda uma diversidade de noções e de modalidades concretas de corpos. Diferentes regimes e modos de produção de corpos que coexistem, rivalizam, se sucedem e se transformam ao longo do tempo. É nesse sentido que Mendes (2006) afirma que, de maneira geral, podemos dizer que Foucault também esteve preocupado com uma história do corpo. Ou seja, concomitantemente à história do sujeito, em certo sentido, Foucault fez também uma história política do corpo. Principalmente se olharmos seus trabalhos sobre a constituição do sujeito moderno.

Em suas análises sobre tal constituição, presentes em Vigiar e Punir e História da sexualidade: a vontade de saber, insere-se, definitivamente, a relação sujeito-corpo-poder. Eizirik (2005) afirma que nesta parte de sua obra, Foucault coloca o problema do poder e do corpo, descrevendo o exercício do poder sobre o corpo. Aqui, inicia suas análises sobre o Biopoder que, segundo Duarte (2006), refere-se a um certo poder que intervém sobre a vida que se desenvolveu em duas formas principais. A primeira, diz respeito a uma disposição dos homens no espaço que visa otimizar seu desempenho. Uma forma de organização, divisão e controle do tempo que são desenvolvidas com o objetivo de produzir rapidez e precisão de

\footnotetext{
${ }^{6}$ Fenomenologia, Marxismo e Positivismo.

${ }^{7}$ Para Foucault o poder não é uma substância nem um misterioso atributo, mas um operador que funciona dividindo, envolvido numa prática divisória que fraciona cada um de nós, tanto internamente em si mesmo quanto em relação aos demais. Essas forças, a que ele chama de poder, atuam no que de mais concreto e material temos - nossos corpos. (Veiga-Neto, 2011).
} 
movimentos, ou seja, procedimentos de poder que caracterizam as disciplinas: anátomopolítica ${ }^{8}$ do corpo humano.

Já a segunda forma de poder, como nos revela Candiotto (2010), se volta para o corpoespécie, no corpo transpassado pela mecânica do ser vivo e como suporte dos processos biológicos: a proliferação, os nascimentos e a mortalidade, o nível de saúde, a longevidade, etc. Toda uma série de intervenções e controles reguladores, uma biopolítica da população. Neste ponto específico, Duarte (2006) nos revela que este novo aporte contribuiu para uma melhor compreensão da atuação do poder em sua forma moderna. Segundo o autor, já não se trata simplesmente de regrar comportamentos individuais, mas pretende-se normalizar a própria espécie, bem como regrar, manipular, incentivar e observar macro fenômenos como as taxas de natalidade e mortalidade, as condições sanitárias das grandes cidades, as infecções e contaminações, a duração e as condições da vida etc. Essas duas formas de atuação do poder sobre o corpo nascem em um momento específico na história e não podem ser vistas na antiguidade grega. Elas inauguram uma nova economia nas relações de poder que podem ser vistas atualmente e compõem o que Foucault tratará por governamentalidade ${ }^{9}$. Entende-se assim, que, a partir do século XIX, além de disciplinar condutas, também pretendia-se implantar um gerenciamento planificado da vida das populações. Logo, o que se produz por meio da atuação específica do biopoder não é mais apenas o indivíduo dócil e útil (produzido pelas disciplinas), mas é a própria gestão da vida do corpo social.

Percebe-se nos trabalhos de Foucault que, ao tratar da constituição do sujeito, trata-se também da produção de seus corpos, relacionando-os a formas específicas de atuação do poder. Como assiná-la Barbosa (2014), tais formas se diferem no tempo. Assim, quando nos colocamos a olhar para a obra de Foucault, percebemos nos dois últimos volumes de história da sexualidade, formas de constituição de subjetividade fabricadas segundo procedimentos de uma ética apoiada na reflexão sobre si, não havendo neste processo a presença prescritiva de códigos, interditos, mecanismos disciplinares, tão presentes quando se trata da constituição do sujeito moderno.

Mesmo na antiguidade clássica já se percebem mudanças. Ao investigar o sujeito moral dos séculos I e II de nossa era, visto em História da sexualidade: o cuidado de si, Foucault localiza uma intensificação dos temas de austeridade, no qual uma nova arte de existência se organiza, diferente da vista no século IV a.c, em seu livro História da sexualidade: o uso dos prazeres, no qual a arte da existência se volta muito mais em torno da questão da moderação dos prazeres e do poder que se exerce sobre si a partir dessa moderação. Modificações que nos fazem perceber uma moral mais rigorosa, construída devido à novas configurações políticas, sociais e cívicas que surgiam naquele momento.

Portanto, não se trata de conceber, conforme Furlan e Silveira (2003), uma alma dissociada do corpo, como visto por certas correntes da metafísica clássica, mas sim, uma noção de alma criada diretamente sobre o corpo, em função dos interesses políticos sobre ele concentrados. Em síntese, diferentemente das noções tradicionais que consideram o corpo como prisão da alma, Foucault inverte a máxima, afirmando a alma como prisão do corpo.

Contudo, vale lembrar que tal história realizada por Michel Foucault ocupa-se, como nos diz Prado Filho e Trisotto (2008), não com o corpo objeto da Biologia e da Medicina, ciências especializadas no conhecimento e na intervenção sobre aquilo que ele apresenta como "natural", mas investiga o corpo em sua produção, como sendo objeto de múltiplas técnicas e alvo de práticas diversas: de moralização, normalização, modelização, "capacitação", "treinamento", dentre outras. Nesse sentido é que se dá a importância do tema em questão

\footnotetext{
${ }^{8} \mathrm{O}$ termo "anatomo-política” busca justamente mostrar o caráter político fundamental da produção dos corpos.

${ }^{9}$ Objeto de estudo das maneiras de governar. (Edgardo, Castro. 2009)
} 
para o Educador Físico. Em sua prática diária na escola, o professor dessa área contribui para produção de sentidos e significados atribuídos ao corpo. O que nos remete a Marinho (2015), quando nos mostra que existe também a própria produção do conhecimento sobre o corpo, que acaba por ser um exercício de poder sobre ele. Na concepção foucaultiana, o poder, longe de impedir o saber, o produz.

Assim sendo, um professor de Educação Física escolar que não compreende o corpo em sua produção política e historicamente localizada, pode, por isso, produzir regimes de verdade sobre ele, ditando normas, comportamentos, padrões estéticos, de saúde, qualidade de vida, como um parâmetro de verdade única para seus alunos, se fechando para olhares e sentidos diversos de proposições e formas de se lidar com o corpo. Atualmente, esforços têm sido empreendidos no campo da Educação Física para aproximá-lo à abordagem foucaultiana, que trataremos no tópico a seguir.

\section{Corpo, Michel Foucault e educação física}

No ano de 2013, Bracht e Almeida ${ }^{10}$, publicaram o artigo Esporte, escola e a tensão que os megaeventos esportivos trazem para a Educação Física Escolar, valendo-se do referencial foucaultiano, mais especificamente o texto intitulado $O$ que é a crítica, para se colocarem contrários a certas perspectivas que pretendem submeter à educação física escolar aos princípios do esporte de alto-rendimento.

Direcionando-se ao vocabulário foucaultiano, pode-se dizer que tais autores resistem a possível retomada do regime de verdade ${ }^{11}$ que induz a educação física escolar a assumir os princípios de alto rendimento, como se fossem seus. Diz Foucault (2000) que o regime de verdade não é apenas de ordem ideológica, é também da forma como certas instituições que a produzem exercem poder sobre outras (ibdem).

No campo da Educação Física, há, provavelmente, vários regimes de verdade. Contudo, Lopes (2012) diagnostica um enorme crescimento de publicações com as palavras "promoção da saúde", presentes na Biblioteca Virtual em Saúde - LILACS - entre os anos de 1980 e 2009. A autora afirma que este aumento está ligado a direcionamentos econômicos vinculados às políticas de saúde, tendo em vista a diminuição dos gastos em saúde pública. Sendo assim, políticas de Promoção da Saúde passaram a ser o eixo articulador de todo o sistema de saúde.

Furtado e Szapiro (2012) revelam que neste novo modelo, as políticas não possuem como centralidade curar uma doença, mas intervir em sua origem, antes de seu aparecimento. Sendo assim, amplia-se a intervenção em saúde para além dos indivíduos doentes, o corpo com ausência de doenças passa a ser alvo de uma seria de intervenções e investimentos ${ }^{12}$.

No campo da Educação Física, Alex Branco Fraga, embasando-se fortemente na análise de discurso empreendida por Michel Foucault, problematiza a Educação Física contemporânea a partir da análise da constituição, disseminação e fixação do discurso de vida ativa. Fraga (2006), mostra o exercício da informação em saúde como modo privilegiado de governo dos corpos na atualidade.

\footnotetext{
${ }^{10}$ Eles também publicaram o livro Emancipação e diferença na educação: uma leitura com Bauman, no qual realizam uma releitura de perspectivas que se comunicam com a obra de Michel Foucault.

${ }^{11}$ Entende a verdade como um "conjunto de procedimentos regulados para a produção, a lei, a repartição, a circulação e o funcionamento dos enunciados" ( Foucault, 2000, p.14).

12 Os discursos propositivos sobre melhoria das condições de saúde não são algo novo, a novidade é o lugar central que assume a "promoção" quando se torna núcleo central das políticas de saúde atuais. Furtado e Szapiro (2012)
} 
Desenvolvendo o conceito de biopolítica em Foucault, a partir dos escritos de Deleuze, o autor acentua que na passagem de uma sociedade disciplinar (em que se pretendia a introjeção da disciplina, conforme descrita por Foucault) para uma sociedade dita de controle (descrita por Deleuze), pulveriza-se a forma de exercer o poder, tornando-se mais flexível e monitorando os corpos através da regulação dos fluxos e do acesso à informação. Uma forma de governo que depende de um conjunto de técnicas, procedimentos e saberes que regulam os estilos de vida da população dentro daquilo que o autor chamou de "biopolítica informacional".

A partir de então, Fraga (2006) desenvolve sua análise do discurso dissecando materialidades oriundas dos programas Agita São Paulo, Agita Brasil, Agita Mundo, assim como de grandes eventos organizados pela Organização Mundial de Saúde (OMS). Em seus achados, o autor, localiza a importância que o conceito de Risco adquire como estratégia de coerção deste discurso, assim como o novo mal a ser combatido, o Sedentarismo. Em outro trabalho, Fraga e Finco (2012) revelam como até mesmo os jogos eletrônicos na atualidade passam a compor este quadro discursivo da vida ativa. No entanto, é importante destacar a posição do autor perante esse discurso: ele não faz apologia ao sedentarismo e nem se posiciona contra o estilo de vida ativo. Trata, sim, de investigar os sistemas de significação desta maquinaria ${ }^{13}$ do agito, como ele mesmo se refere, para compreender como nos constituímos na atualidade a partir deste discurso, muito presente no campo da Educação Física.

\section{Conclusão}

Em um texto intitulado, iluminismo e crítica, Foucault, ao discorrer sobre a função de seu modelo de pesquisa, afirma:

Nesse sentido, a crítica genealógica da modernidade procura mostrar que trazer à tona os "jogos de correlações de forças", a constituição dos saberes e poderes modernos e sua produção histórica como "verdade" presente nas práticas sociais, evidencia, sobretudo, a atitude política e ética de lutar contra as práticas de sujeição atuais. (FOUCAULT, apud: ASSMANN E NUNES, 2007, p.15)

É neste sentido que também vislumbramos nossa contribuição. Ao longo deste artigo procuramos fazer um breve resumo histórico da discussão sobre o corpo na disciplina escolar Educação Física, assim como, apresentar a forma que o conceito de corpo adquire na obra de Michel Foucault. Pensamos que, compreender o corpo e a Educação Física escolar a partir da perspectiva apresentada, garante aos professores de educação física escolar a possibilidade de um certo distanciamento crítico de sua prática cotidiana, tendo em vista, a problematização das diferentes disputas pela verdade no qual estão submersos, orquestradas, muitas vezes, ao governo da população.

Parafraseando Foucault (1999), a luta para não ser governado, ou para não ser governado exageradamente ou ser excessivamente subjetivado, refere-se ao permanente questionamento de nossas experiências. Observando a educação física contemporânea, nos perguntamos: a função do professor de educação física escolar atualmente se refere apenas ao domínio de diferentes códigos prescritivos sobre o uso "correto" do corpo com o objetivo de evitar problemas de saúde e promover a boa forma ou estaria aí a captura dos educadores físicos para o projeto de um novo estado cuja marca mais evidente é a restrição de gastos públicos? Ainda teremos a coragem de justificar nossa prática a partir de certos discursos, supostamente

\footnotetext{
${ }^{13}$ Termo que compreende a análise do funcionamento do poder em Michel Foucault. O poder não parte de alguém ou um ponto específico, funciona como uma maquinaria sem maquinista. 
neutros, apenas para conquistarmos a tão sonhada legitimidade dentro da escola e no mercado de trabalho ou teríamos a obrigação de ajudarmos nossos alunos a liberarem seus corpos das inúmeras imposições sociais sobre eles?

Pode ser que, diante das cobranças sociais, façamos isso como estratégia de sobrevivência, uma carta de apresentação para os ouvidos afoitos pelo governo dos outros, mas, não poderíamos também nos reinventar? A educação física, como outro componente curricular qualquer, também pode ser terreno fértil para uma reinvenção, não só dela, mas da própria escola. Reinventar conteúdos, formas de transmissão dos saberes, formas de se relacionar com os alunos, etc. Pensar a constituição de nossos corpos utilizando a história como referência e problematizar nossa prática no presente, pode ser um bom caminho para fazer da escola através desta disciplina um lugar mais interessante.

\title{
BODY FOR MICHEL FOUCAULT AND HIS PRESENCE TO THE PHYSICAL EDUCATION AREA
}

\begin{abstract}
Since 1980s, we can see a growth of Human Sciences influence in the Physical Education area that. Such influences culminate in new body researches, different of the old researches which investigated only biological aspects. Since then, the new ways to investigate "Body" have in common political, cultural and historical aspects. In this scenario Michel Foucault's thought causes some effects with theoretical foundation of the Body's concept. This article investigates Michel Foucault ideas from expert Brazilian commentators. We intend to know how "Body" and "Subject" concepts are presented for this philosopher. It is understood that such an analysis has its validity for a better understanding of discussions in the contemporary scenario of Physical Education.
\end{abstract}

Keywords: Body, Subject, Michel Foucault, Physical Education .

\section{CUERPO EN EL TRABAJO DE MICHEL FOUCAULT Y SU PRESENCIA EN EL CAMPO DE LA EDUCACIÓN FÍSICA}

\section{Resumen}

Debido una creciente influencia de Ciencias Humanas en el área de Educación Física, que se ha desarrollado a partir de los ideales de Ciencias Biológicas, surgen nuevas formas de investigación del Cuerpo que tienen en comunes aspectos políticos, culturales e históricos. En el centro de este escenario está Michel Foucault. Este artículo investiga las obras de lo mismo y comentaristas, cómo es la base del concepto de cuerpo en su forma de pensar. Se entiende a partir del análisis, el cuerpo visto como un material de superficie, que instala diferentes formas de sujeto realizada por tecnologías históricas y políticas específicas. Se entiende que este tipo de análisis tiene su validez para una mejor comprensión de problematizaciones en el escenario contemporáneo de Educación Física.

Palabras clave: Cuerpo. Sujeto. Michel Foucault. Educación Física.

\section{Referências}

ALMEIDA, F; BRACHT, V. Emancipação e diferença na educação: uma leitura com Bauman. Campinas, SO: Autores Associados, 2006. 
ALMEIDA, F; BRACHT, V. Esporte, escola e a tensão que os megaeventos esportivos trazem para a Educação Física Escolar. Em Aberto, Brasília, v.26, n.89, p.131-143, jan/jun. 2013.

ARAÚJO, I. L. Foucault e a crítica do sujeito. 2. ed. Curitiba: UFPR, 2008.

ASSMANN, S; NUNES, N. Michel Foucault e a genealogia como crítica do presente. Revista Internacional Interdisciplinar Interthesis, Florianópolis, v.4, n.1, jan/jun. 2007.

BARBOSA, P. P. A análise da noção de sujeito em Foucault: um estudo para compreensão do debate contemporâneo entre Modernidade e Pós-modernidade na Pedagogia. Filosofia Capital, Brasília, v. 9, p. 6-21, 2014.

BRACHT, V. A constituição das teorias pedagógicas da educação física. Cadernos Cedes. $n$. 48, agosto, 1999.

CANDIOTTO, C.; NETO, A. V. (Orgs.). Foucault e a crítica da verdade. Belo Horizonte: Autêntica; Curitiba: Champagnat, 2010. (Coleção Estudos Foucaultianos).

CASTRO, E. Vocabulário de Foucault - Um percurso pelos seus temas, conceitos e autores. Tradução de Ingrid Muller Xavier. Belo Horizonte: Autêntica, 2009.

DAOLIO, J. Da Cultura do Corpo. 17. ed. São Paulo: Papiros, 2013.

DANAILOF, K. ; SOARES, C. Corpos e cidades: lugares da educação. 2002. Dissertação (Mestrado em Educação) - Faculdade de Educação Física, Universidade Estadual de Campinas, São Paulo, 2002.

DANAILOF, K. Imagens da infância: Educação e o corpo em 1930 e 1940 no Brasil. Rev. Bras. Cienc. Esporte, São Paulo, v. 26, n. 3, p. 25-40, maio, 2005.

DANTAS JUNIOR, H. A esportivização da Educação Física no século do espetáculo: reflexões historiográficas. HISTEDBR On-line, São paulo, n. 29, p. 215-232, março, 2008.

DREYFUS, H. L.; RABINOW, P. Michel Foucault uma trajetória filosófica: para além do estruturalismo e da hermenêutica. 2. ed. Rio de Janeiro: Forense Universitária, 2010.

DUARTE, A.; RAGO, M.; VEIGA, N. A. (Orgs.). Biopolítica e resistência - o legado de Michel Foucault. Belo Horizonte: Autêntica, 2006, p. 45-55. (Coleção Figuras de Foucault).

EIZIRIK, M. F. Michel Foucault: Um pensador do presente. 2. ed. Ijuí: Unijuí, 2005.

FERNANDES, C. Discurso e sujeito em Michel Foucault. São Paulo: Intermeios, 2012.

FINCO, M; FRAGA, A. O corpo abduzido da realidade para virtualidade - Imersão sensorial, movimentação interativa e vida ativa. p. 65 - 83. In COUTO, E; GOELLNER S. O triunfo do Corpo. Petrópolis, RJ: Vozes, 2012.

FONSECA, M. Michel Foucault e a constituição do sujeito. 3 ed. São Paulo: EDUC. 2011. 
FOUCAULT, M. A ordem do discurso. 22.ed. São Paulo: Editora Loyola, 2012.

FOUCAULT, M. As palavras e as coisas: uma arqueologia das ciências humanas. Tradução de Salma Tannus Muchail. 9. ed. São Paulo: Martins Fontes, 1981 (2007).

FOUCAULT, M. Em defesa da sociedade. São Paulo: Martins Fontes. 1999.

FOUCAULT, M. História da sexualidade I: a vontade de saber. Graal, 1988.

FOUCAULT, M. História da sexualidade II: o uso dos prazeres. Tradução de

Maria Thereza da Costa Albuquerque e J. A. Guilhon Albuquerque. 13. ed. Rio de Janeiro: Graal, 1984 (2012).

FOUCAULT, M. História da sexualidade III: o cuidado de si. Tradução de

Maria Thereza da Costa Albuquerque e J. A. Guilhon Albuquerque. 11. ed. Rio de Janeiro: Graal, 1985 (2011).

FOUCAULT, M. Microfísica do Poder. Organização e Tradução de Roberto Machado. Rio de Janeiro: Edições Graal, 1984 (2000).

FOUCAULT, M. Iluminismo e crítica. (trad. provisória do italiano de Selvino José Assmann) Paris: Boletim da Sociedade Francesa de Filosofia, n. 2, abr./jul. 1990.

FOUCAULT, M. O que é a crítica. Roma: Donzelli Editore, 1999.

FOUCAULT, M. Vigiar e Punir: nascimento da prisão. Tradução de Raquel Ramalhete. 39. Ed. Rio de Janeiro: Vozes, 1975 (2011).

FRAGA, A. Exercício da informação: governo dos corpos no mercado da vida ativa. Campinas, SP: Autores Associados, 2006.

FURTADO, M.; SZAPIRO, A. Promoção da saúde e seu alcance biopolítico: o discurso sanitário da sociedade contemporânea. Saúde soc. São Paulo, v. 21, n.4, out./dez., 2012.

HEROLD, C; LEONEL Z. A Educação Física e a criação dos sistemas nacionais de ensino: da prática social à prática escolar. Maringá: Eduem, 2010.

LOPES, A. Saúde no processo de democratização brasileiro: promoção da saúde, biopolíticas e práticas de si na constituição de sujeitos da saúde. 2012. Tese (Doutorado em Psicologia) - Pós-graduação em Psicologia, Universidade Federal de Santa Catarina, 2012.

LOURO, G. L. Corpo, escola e identidade. Educação e Realidade. v. 25, n. 2, p. 59-76, jul./dez., 2000.

LUDORF, S. Panorama da Pesquisa em Educação Física da década de 90: Análise dos resumos de dissertações e teses. Revista da Educação Física/UEM, Maringá, v. 13, n. 2, p. 1925, 2. sem., 2002.

MACHADO, R. Foucault, a ciência e o saber. 4. ed. Rio de Janeiro: Jorge Zahar, 2007. 
MARINHO, C. Corpo heterotópico como resistência aos processos de subjetivação identitária: algumas questões filosófico-educacionais. In: IX COLÓQUIO INTERNACIONAL MICHEL FOUCAULT: Michel Foucault e as heterotopias do corpo, 2015, Recife.

MARTINELI, T.; MILESKI, K. Concepções de “corpo" na Educação Física: apontamentos históricos. In: IX ANPED SUL: seminário de pesquisa em Educação da região sul, 2012.

MAZONI, A. Corpo e movimento no cotidiano de uma escola "plural": um estudo de caso. 2003. Dissertação (Mestrado em Educação) - Pós-graduação em Educação, Faculdade de Educação da UFMG, Belo Horizonte, 2003.

MEDINA, J; HUNGARO, E; BRACHT, V. A educação física cuida do corpo... e "mente": Novas contradições e desafios do século XXI. São Paulo: Papirus, 2010.

MENDES, C. O corpo em Foucault: superfície de disciplinamento e governo. Revista de Ciências Humanas, Florianópolis, n. 39, p. 167-181, abril, 2006.

NUNES, M.; RÚBIO, K. O(s) Currículo(s) da Educação Física e a constituição da identidade de seus sujeitos. Currículo sem fronteiras, v. 8, n. 2, p. 55-77, jul./dez., 2008.

OLIVEIRA, T. Educação física escolar e ditadura militar no Brasil: (1964-1984) Entre a adesão e a resistência. Revista Brasileira Ciência e Esporte, Campinas, v. 25, n. 2, p. 9-20, janeiro, 2004.

OLIVEIRA, T. Educação do corpo na Escola brasileira. São Paulo: Autores associados, 2006.

PINTO, J. Representações de esporte e educação física na ditadura militar: Uma leitura a partir da revista de história em quadrinhos Dedinho (1969-1974). 2003. 154 f. Dissertação (Mestrado em Educação) - Faculdade de Educação de Minas Gerais, Universidade Federal de Minas Gerais, UFMG, Minas Gerais, 2003.

PRADO FILHO, K; TRISOTTO, S. O corpo problematizado a partir de uma perspectiva histórico-política. Psicologia em Estudo, Maringá, v. 13, n. 1, p. 115-121, jan./mar., 2008.

SANTOS, L. Pedagogias do Corpo: Representação, Identidade e Instâncias de Produção. Rio de Janeiro: Vozes, 1999.

SILVEIRA, F; FURLAN, R. Corpo e Alma em Foucault: postulados para uma metodologia da psicologia. Psicologia USP, São Paulo, p. 171-194, 2003.

SOARES, C. Pesquisas sobre o corpo: ciências humanas e educação. São Paulo: Autores Associados, 2007.

SOARES, C. Educação Física: raízes européias e Brasil. São Paulo: Autores Associados, 1994.

SOUSA, E.; VAGO, T. Última década dos oitocentos, primeira década da Gymnastica na formação do professorado mineiro. p. 253-281. In: VEIGA, C; FONSECA, T. História e Historiografia da Educação no Brasil. Belo Horizonte: Autêntica, 2003. 
TEIXEIRA, A. H. L. A "Gymnastica" no Ginásio Mineiro: Internato e externato (1890 1916). p. 236-254. In: VAGO, T; OLIVEIRA, B. Histórias de Práticas Educativas. Belo Horizonte: UFMG, 2008.

VAGO, T. Início e fim do século XX: Maneiras de fazer educação física na escola. Cadernos Cedes. n. 48, agosto, 1999.

VEIGA NETO, A. Foucault e a Educação. 3. ed. Belo Horizonte: Autêntica, 2011.

Recebido em: 08/07/2016

Revisado em: 15/08/2016

Aprovado em: 16/08/2016

Endereço para correspondência:

pietrinepaiva@hotmail.com

Pietrine Paiva Barbosa

Universidade Federal de Minas Gerais

Av. Pres. Antônio Carlos, 6627

Pampulha, Belo Horizonte - MG, 31270-901 